Table 2 Patient numbers in Sudan, 2005 and 2006, by gender and diagnosis

\begin{tabular}{|c|c|c|c|}
\hline & Male & Female & Total \\
\hline \multicolumn{4}{|c|}{ Total numbers of patients discharged } \\
\hline \multicolumn{4}{|c|}{ Schizophrenia } \\
\hline 2005 & 530 & 308 & 838 \\
\hline 2006 & 1175 & 788 & 1963 \\
\hline \multicolumn{4}{|c|}{ Other psychosis } \\
\hline 2005 & 867 & 718 & 1585 \\
\hline 2006 & 1575 & 1237 & 2812 \\
\hline \multicolumn{4}{|l|}{ Epilepsy } \\
\hline 2005 & 505 & 334 & 831 \\
\hline 2006 & 564 & 825 & 1419 \\
\hline \multicolumn{4}{|c|}{ Out-patient attendance } \\
\hline \multicolumn{4}{|c|}{ Schizophrenia } \\
\hline 2005 & 3157 & 2072 & 5229 \\
\hline 2006 & 4136 & 2739 & 6875 \\
\hline \multicolumn{4}{|c|}{ Other psychosis } \\
\hline 2005 & 4331 & 4342 & 8673 \\
\hline 2006 & 10134 & 9525 & 19659 \\
\hline \multicolumn{4}{|l|}{ Epilepsy } \\
\hline 2005 & 2812 & 2204 & 5016 \\
\hline 2006 & 4357 & 3682 & 8039 \\
\hline
\end{tabular}

\section{The burden of mental illness}

Total numbers of patients, by diagnosis and gender, for both 2005 and 2006, are given in Table 2.

\section{References}

Ahmed, I. M., Bremer, J. J., Magzoub, M. M. E., et al (1999) Characteristics of visitors to traditional healers in central Sudan. Eastern Mediterranean Health Journal, 5, 79-85.

Sudan Federal Ministry of Health National Information Centre. The Annual Health Statistical Report 2005-2006.

World Health Organization (2001) Sudan Country Profile. WHO.

World Health Organization (2001) World Health Day Documents 2001. Mental Health as Part of Primary Health Care: Highlights from the Region. WHO, EMRO.

World Health Organization (2006) Mental Health in the Eastern Mediterranean Region: Reaching the Unreached. WHO Regional Publications, Eastern Mediterranean Series.

\title{
Use of participatory, action and research methods in enhancing awareness of mental disorders in Kariobangi, Kenya
}

\section{Caleb J. Othieno, ${ }^{1}$ Nelly Kitazi, ${ }^{2}$ James Mburu, ${ }^{1}$ Anne Obondo, ${ }^{1}$ Muthoni A. Mathai ${ }^{1}$ and Rene Loewenson ${ }^{3}$}

'Department of Psychiatry, PO Box 19676, Kenyatta National Hospital, 00202 - KNH, Nairobi, Kenya, email cjothieno@uonbi.ac.ke; ${ }^{2}$ Mathari Hospital, Nairobi, Kenya; ${ }^{3}$ Training and Research Support Centre, EQUINET

W orldwide, mental disorders affect 450 million people and account for $15 \%$ of the overall burden of diseases from all causes (World Health Organization, 2001). Two-thirds of those affected do not receive adequate care owing to stigma, discrimination, neglect and poverty. The World Health Organization (2001) found that only $1 \%$ of the total health expenditure went to mental health in most countries.

In Kenya, service provision is further impeded by limited facilities and lack of mental health workers. Milder forms of psychiatric disorder (especially those affecting children, who comprise a large part of the population) are not adequately identified (Kiima et al, 2004). Plans to increase access to mental health services mainly use the top-down approach, instead of involving community members in planning. The First Kenya National Mental Health Programme of Action, in 1996, emphasised the need for the development of infrastructure and the training of mental health workers but gave little detail on community involvement, although it recognised the need to improve community services. This paper describes an attempt to involve community members and primary health workers in identifying and working out solutions to mental health problems in a socio-economically disadvantaged area in Nairobi, Kenya, using participatory, reflection and action (PRA) methods. PRA methods empower people to share, analyse, enhance their knowledge and plan further actions after evaluation and reflection (Wadsworth, 1998). Although the methods have been used successfully in other areas of rural development, their use in relation to psychiatric services has not been reported in Kenya.

\section{Method}

Over a 6-month period, in 2007, 30 community members from Kariobangi and community mental health workers based at Mathari Hospital were selected and engaged in a PRA process to identify mental health challenges and to enhance the community's problem-solving capacity. During the first meeting, a baseline questionnaire was administered to assess the participants' perception of mental health and the stigma associated with it, and the role of families and social organisations in promoting mental health. Thereafter, concepts of mental health were discussed using health pictures. Through brainstorming and group discussions, the mental health problems were ranked and scored on charts 
by the participants. Working in groups, they drew up lists of stakeholders in the community and a community map. The relationships between the various institutions were shown in Venn (chapatti) diagrams and possible entry points were identified. They further identified important areas, which they later visited during a walk in the community (transect walk), and important people, whom they interviewed. Using the information gathered and the insights gained, the participants discussed and agreed on what could be done to reduce mental health problems in the community. The actions were ranked using beans arranged on paper to help them visualise the process. After a period of intervention, the actions were assessed by the participants using a wheel chart. This is a quick, qualitative method of measuring progress, using lines drawn in a circle (Loewenson et al, 2006).

\section{Results}

The baseline survey showed that the mental health workers' knowledge of mental disorders was moderate, while those from the community thought they had poor knowledge. However, the scores of the two groups did not differ significantly. Over $80 \%$ of the participants thought that mental illness in the community was extremely common. The majority attributed mental illness to afflictions of the mind and poverty. They identified stress and depression followed by alcohol and substance use and epilepsy as major problems in the community. Childhood psychiatric disorders, apart from intellectual disability, ranked lower. Obstacles identified included lack of support from the local administration, inadequate medication, high cost of drugs, stigma, long distance to the referral hospital and inappropriate clinic timing.

A social map of the area revealed several organisations dealing with children, youths, widows, orphans, the elderly, and those with HIV/AIDS. In addition, there were privately run schools that provided free meals. They felt that apart from the health institutions, other organisations offered little help to people who are mentally ill.

Key people interviewed included the chief, church leader, community clinic workers, and teacher. Their views on common mental disorders were similar to those described above. They agreed that more collaboration was needed and that tighter controls on alcohol and drug use were necessary. Children with an intellectual disability and orphaned children in the community needed more support. The participants felt that the administrative and security officers were very important, as they had a big role to play in regulating drugs in the community and licensing outlets to sell alcohol.

Reflecting on the findings, the group agreed that, with the available resources, they could increase awareness of mental health problems through public education, establish an additional community clinic, provide adequate drugs at the existing clinics, advocate tighter controls on the sale of alcohol, and provide sheltered workshops and day care centres for people with an intellectual disability. The participants suggested that they should start a mental health promotion and support group within the community. The family members of those with mental illness would organise themselves into groups with the help of the health staff. These groups would identify available resources and coordinate mental health programmes within the community.
The participants could not agree on how to alleviate poverty, although they regarded it as a major cause of mental ill health. Options considered included starting incomegenerating small-scale businesses and strengthening self-help groups with the resource of invited experts. At the meeting, individuals volunteered for the various actions.

\section{Follow-up meeting}

A feedback meeting was held 6 months after the initial assessment. The community members' perception of mental illness had changed and they believed the burden of mental illness was greater than they had initially thought. They had increased awareness of mental illnesses and their causes.

Some of the specific targets identified earlier had been met. Hospital psychiatrists had given talks on mental health to the local school and church. A community health nurse had been invited to the local chiefs' meeting and mental health personnel had participated in meetings of local social groups. An occupational therapist from Mathari Hospital had started working with children with intellectual disabilities in one of the community organisations. A request had been made to the Ministry of Health for adequate supplies of antidepressants and anti-epileptic drugs for the clinics.

\section{Discussion}

The results show the three phases of the PRA process participation in identifying problems, reflection on possible solutions using local resources, and action. The community members welcomed the project and were more confident in discussing mental health disorders and possible interventions at follow-up. Initially, the participants had high expectations of outside aid. Being unfamiliar with PRA methods, they were at first surprised that they were expected to come up with solutions to their problems but, after explanation, this was overcome. The PRA methods used, such as ranking, scoring, drawing and the group discussions, were easily implemented, unlike reflective discussions. Most of the participants expected the facilitators to give them the solutions while they played a more passive role. They were repeatedly reminded that the community affected had better knowledge of the problems and could offer useful solutions.

Lack of coordination and poor communication between the various social groups in the community resulted in poor care for people who are mentally ill. Community members are willing to work with mental health workers to improve healthcare in the community but need to be given support.

\section{Conclusions}

Further interventions and evaluation of the impact of the PRA methods as a means of giving the community a voice in mental health issues are needed. The next phase of the project will focus on substance use in the community.

\section{Acknowledgements}

We thank Kariobangi community members and the staff of Mathari Hospital, especially Lorna Osendi, Teresia Mbugua, Jesca Papi and Pastor Erastus Omuhanga, for their important contributions to this work. This 
work was implemented under the theme 'work on participatory methods in health' in the Regional Network for Equity in Health in East and Southern Africa (EQUINET) with support from SIDA Sweden.

\section{References}

Kiima, D. M., Njenga, F. G., Okonji, M. M. O., et al (2004) Kenya mental health country profile. International Review of Psychiatry, 16, 48-53.
Loewenson, R., Kaim, B., Mbuyita, S., et al (2006) Participatory Methods for People Centred Health Systems: A Toolkit for PRA Methods. TARSC, Ifakara (Harare).

Wadsworth, Y. (1998) What is participatory action research? Action Research International, Paper 2. Available at http://www.scu.edu.au/schools/gcm/ ar/ari/p-ywadsworth98.html (last accessed November 2008).

World Health Organization (2001) The World Health Report: mental disorders affect one in four people. Available at http://www.who. int/whr/2001/media_centre/press_release/en/index.html (last accessed November 2008)

\section{Psychiatric practice for intellectual disability in the USA: challenges and advances}

\section{Stephen Ruedrich MD}

Associate Professor of Psychiatry, Case School of Medicine, MetroHealth Medical Center, 2500 MetroHealth Drive, Cleveland, Ohio 44109, USA, email sruedrich@metrohealth.org

\begin{abstract}
ndividuals with intellectual disability are thought to make up at least $1 \%$ of the population, and it is estimated that approximately one-third of them have a comorbid psychiatric disorder (Harris, 2006). These 'dually diagnosed' individuals present a particular diagnostic and therapeutic challenge. A difficulty facing psychiatry in the USA over the past several decades has been to interest and educate a sufficient number of psychiatrists to meet the mental health needs of this group of patients (Department of Health and Human Services, 2002).

Most individuals with the dual diagnosis of intellectual disability and psychiatric disorder live in community settings, with families, or in small congregate facilities such as group homes, or in individual apartments with supported living assistance (Harris, 2006). Even at a peak in the mid-1960s, only about 190000 of the estimated three million persons with intellectual disability resided in large institutional settings in the USA, and over the past 40 years this number has shrunk to about 40000 (Prouty et al, 2007). Some states have completely closed such large institutions, and all states have focused on keeping persons with intellectual disability living and working in their own communities. This evolution to primarily community-based care has increased the need for adequate psychiatric services in both rural and urban settings, and provided an impetus for expanded education.
\end{abstract}

\section{The challenges}

Unfortunately, this need goes largely unmet, as there are insufficient numbers of psychiatrists with education, experience and skills in this area. In a 1965 survey conducted by the American Psychiatric Association (APA), 144 of 16500 psychiatrists (nearly 1\%) identified intellectual disability as their main area of work (Whiting, 1969). Since then, interest in the psychiatry of intellectual disability has seemingly attenuated in the USA, at least as revealed by membership and participation in professional organisations dedicated to this specialty. The National Association for the Dually Diagnosed (NADD), perhaps the US group most closely allied with dual diagnosis issues, has fewer than 100 psychiatrist members, and some of them are from outside the USA (NADD, 2007). Other professional organisations have similar or smaller numbers of psychiatrists who identify intellectual disability as their professional focus.

One possible reason for this lack of interest is confusion regarding whether the care of persons with intellectual disability and dual diagnosis should be the province of general psychiatry, or whether post-residency specialised training and certification in intellectual disability should be provided. Currently, the Residency Review Committee (RRC) for Psychiatry of the Accreditation Council for Graduate Medical Education (ACGME) in the USA provides no specific requirement for education in intellectual disability in general psychiatric training programmes (ACGME, 2007). This means many or even most general psychiatrists have little or no exposure to, or experience with, persons with intellectual disability during general residency education.

The situation is little better with regard to post-residency specialised training. Only in child and adolescent psychiatry fellowship training does the RRC for Psychiatry mention any need for specialised education: 'There must be an organized teaching and clinical experience in pediatric neurology, mental retardation, and other developmental disorders' (ACGME, 2007). However, the American Board of Psychiatry and Neurology (ABPN) reports that, at present, there are no accredited post-residency fellowships in the psychiatry of intellectual disability in the USA (ABPN, 2007). Perhaps the closest equivalent is fellowship training in neurodevelopmental disabilities, which is considered a sub-specialty of neurology. The ABPN approved fellowship education in neurodevelopmental disabilities in 1999, and held the first qualifying examination in 2001 (ABPN, 2007). Applicants for the certifying examimation must complete 2 core years 